\title{
Diet, smoking and cardiovascular risk in people with schizophrenia
}

\author{
Descriptive study \\ ROBIN G. MCCREADIE on behalf of the SCOTTISH SCHIZOPHRENIA \\ LIFESTYLE GROUP
}

\begin{abstract}
Background Physical health of people with schizophrenia is poor and they die early from cardiovascular disease.
\end{abstract}

\begin{abstract}
Aims To describe the lifestyle of people with schizophrenia through diet, smoking habits, weight and exercise, and to report risk of coronary heart disease (CHD).
\end{abstract}

\begin{abstract}
Method Dietary habits of 102 community-dwelling people with schizophrenia were assessed by the Scottish Health Survey Questionnaire. Also assessed were smoking habits, physical activity, biochemical indices of nutrition and future risk of CHD.
\end{abstract}

Results Fewer males, compared with the general population, reached acceptable levels for consumption of fruit, vegetables, milk, potatoes and pulses. Fewer females reached the levels for consumption of milk and potatoes. Mean number of fruit and vegetable portions consumed per week was 16 (s.d.=14); 71 (70\%) were smokers; 25 (86\%) females and 50 (70\%) males were overweight or obese; 59 (59\%) considered themselves physically active; 46 (53\%) had a raised cholesterol:high-density lipoprotein ratio, and 64 (74\%) a low $\alpha$-tocopherol: cholesterol ratio. Mean 10 -year risk of $\mathrm{CHD}$ in males was $10.5 \%$ $($ s.d. $=8)$ and in females $7 \%($ s.d. $=6)$.

Conclusions The lifestyle of people with schizophrenia must give cause for concern in relation to $\mathrm{CHD}$. Care from secondary care services must address physical as well as mental health.

Declaration of interest Funded by Chief Scientist Office, Scottish Executive.
Most people with schizophrenia live outside hospital, where they remain among the most vulnerable members of our community. Their physical health is often poor (Phelan et al, 2001) and they die early, especially from cardiovascular disease (Mortensen \& Juel, 1993), in which poor diet, physical inactivity, obesity and smoking all contribute importantly. With regard to diet, a high intake of fruit and vegetables may help to prevent cardiovascular disease (Gillman, 1996). We have shown already in a small study (McCreadie et al, 1998) that community-dwelling people with schizophrenia, compared with members of the general population, were making poor dietary choices and most were overweight or obese. Another study (Brown et al, 1999) reported broadly similar results. In the present study we describe in more detail the dietary habits of a much larger group, with special reference to fruit and vegetable intake, and compare them with members of the general population. In addition, we report their smoking habits, the physical exercise they take, biochemical indices of nutritional status and their predicted future risk of coronary heart disease and stroke. Patients recruited for this study are participants in a randomised controlled trial of a dietary intervention, namely the provision of free fruit and vegetables for a 6-month period; this will be reported at a later date.

\section{METHOD}

\section{Patients}

Patients with a DSM-IV diagnosis of schizophrenia (American Psychiatric Association, 1994) were recruited from those living in the community in rural Nithsdale, south-west Scotland, and in urban Partick, west Glasgow, Scotland. The patients approached were all those supported in their homes by mental health care workers, including National Health Service personnel (e.g. attendance at day hospitals, regularly supported at home by community psychiatric nurses) and those working in the independent sector (e.g. Dumfries \& Galloway Mental Health Association, Richmond Fellowship). Patients live on their own or 2-11 in a house. The patients are encouraged to be responsible for their own domestic chores, including shopping and cooking; they made their own dietary choices. The patients in this study were no longer living with family for various reasons but their position in the community had been assessed as sufficiently precarious for them to need additional support. A generation ago it is likely that such patients would have been in long-stay psychiatric wards.

All patients gave written informed consent and the study was approved by the relevant local research ethics committees.

\section{Assessment}

The patients' diet was assessed by one of two research nurses using the food frequency section of the Scottish Health Survey questionnaire (Scottish Executive Health Department, 1998). In this section there is, among other things, a specific assessment of fruit and vegetable intake. The questionnaire assesses food intake retrospectively. Smoking habits were assessed by a questionnaire recently used in a survey of the general population in south-west Scotland (Waldron et al, 1995). A non-fasting blood sample was taken to measure plasma folate, glucose, vitamins $\mathrm{C}$ and $\mathrm{E}$, carotenoids, serum total cholesterol and high-density lipoprotein (HDL) cholesterol. Plasma folate, vitamin E and glucose and serum lipids were measured in the biochemistry and haematology laboratories, Dumfries \& Galloway Royal Infirmary. Plasma vitamin $\mathrm{C}$ and serum vitamins $\mathrm{A}$ and $\mathrm{E}$ and carotenoids were measured at the Rowett Research Institute, Aberdeen. Also measured was body weight, height and waist circumference. The body mass index (BMI) (weight $/$ height $^{2}, \mathrm{~kg} / \mathrm{m}^{2}$ ) was calculated. The level of physical activity was recorded using the Scottish Physical Activity Questionnaire (Lowther et al, 1999). Future risk of coronary heart disease and stroke was estimated using the Framingham assessment and associated computer program (Hingorami \& Vallance, 1999). This assessment includes such things as age, gender, smoking status, blood pressure, left ventricular hypertrophy (assessed by electrocardiogram), plasma glucose and 
Table I Social and demographic data

\begin{tabular}{lc}
\hline $\begin{array}{l}\text { Male/female } \\
\text { Age, years } \\
\text { Mean (s.d.) }\end{array}$ & 72 (7l\%)/30 (29\%) \\
$\begin{array}{l}\text { Length of illness, years } \\
\text { Mean (s.d.) }\end{array}$ & $45(13)$ \\
Marital status & 21 (13) \\
Single & \\
Married & $82(80 \%)$ \\
Divorced/separated & $3(3 \%)$ \\
Widowed & $14(14 \%)$ \\
Domiciliary status & $3(3 \%)$ \\
Lives alone & $56(55 \%)$ \\
Lives with other patients & $4 \mathrm{I}(40 \%)$ \\
Other & $5(5 \%)$ \\
\hline
\end{tabular}

serum total cholesterol and HDL cholesterol. A psychiatrist assessed the patients' mental state using the Positive and Negative Syndrome Scale (PANSS) for schizophrenia (Kay et al, 1987). The length of illness also was recorded, as was current medication.

\section{Statistics}

Differences between groups were tested by $\chi^{2}$, Fisher exact or $t$-tests as appropriate. Associations were measured by Pearson's correlation. Two-tailed tests were used.

\section{RESULTS}

A total of 186 patients were approached to participate in a study that was not only descriptive but examined dietary intervention (see above). Of these patients, 102 $(54 \%)$ consented. Those who consented did not differ in gender distribution, mean age and living arrangements from those who refused.

Social and demographic data of the 102 who entered the study are shown in Table 1. Males were younger than females (mean age $=43$ years $($ s.d. $=12) v .50$ (s.d. $=$ 14); $t$-test, $t=2.69$, d.f. $=100, P=0.008)$ and more had never married (63/72 v. 19/ $30 ; \chi^{2}=6.39$, d.f. $\left.=1, P=0.01\right)$. Two patients $(2 \%)$ reported that they had diabetes.

As part of the intervention study (see above) about one-third of patients were assessed by occupational therapists, who learned that all were unemployed and the mean amount of money they had available to spend on food was $£ 28$ per week (range $£ 15-60)$.

\section{Dietary habits}

A comparison of the patients' general diet with that of the general population of Scotland was made through reference to the dietary section of the Scottish Health Survey 1998 (Scottish Executive Health Department, 1998). This survey describes the dietary choices of adult males and females in terms of frequency with which certain food groups, both healthy and unhealthy, are consumed.

The Scottish dietary targets for 2005 were outlined in the Diet Action Plan for
Scotland (Scottish Office Department of Health, 1996) and further endorsed in the Scottish Office White Paper on health, Towards a Healthier Scotland (Scottish Office Department of Health, 1999). Where possible we have compared our patients' dietary choices with the summary findings of the Scottish Health Survey data, which most closely reflect the aspirational targets of the Diet Action Plan for Scotland (Table 2). Fewer males with schizophrenia than males in the general population reached acceptable levels for the consumption of fresh fruit, vegetables, skimmed or semi-skimmed milk, potatoes, pasta or rice, and pulses. More male patients than those in the general population were frequently consuming breakfast cereal. Fewer females with schizophrenia than females in the general population reached acceptable levels for the consumption of skimmed or semi-skimmed milk, potatoes, pasta or rice.

The mean number of portions of fruit and vegetables consumed each week was 16 (s.d.=14). This was made up of fruits (mean number of portions $=7$, s.d. $=10$ ), vegetables $($ mean $=6$, s.d. $=6)$ and fruit juice (mean $=3$, s.d.=7). Females ate more vegetables than males $\quad($ mean $=8 \quad($ s.d. $=7) \quad v . \quad$ mean $=5$ (s.d. $=5$ ); $t$-test: $t=2.58$, d.f. $=100, P=0.01$ ). The Scottish dietary targets for 2005 stipulate an increase of average fruit and vegetable consumption to 400 grams per day, which equates with 35 portions per week.

The results presented so far have compared the patients with the general

Table 2 Dietary choices of patients and of the general population of Scotland

\begin{tabular}{|c|c|c|c|c|c|c|}
\hline & \multicolumn{3}{|c|}{ Males } & \multicolumn{3}{|c|}{ Females } \\
\hline & $\begin{array}{l}\text { Patients } \\
(n=72)\end{array}$ & $\begin{array}{l}\text { General population' } \\
\qquad(n=394 I)\end{array}$ & $P\left(\chi^{2}\right)$ & $\begin{array}{l}\text { Patients } \\
(n=30)\end{array}$ & $\begin{array}{l}\text { General population' } \\
\qquad(n=5106)\end{array}$ & $P\left(\chi^{2}\right)$ \\
\hline & $\%$ & $\%$ & & $\%$ & $\%$ & \\
\hline Fresh fruit once a day or more & 33 & 46 & 0.04 & 43 & 59 & 0.12 \\
\hline Fruit juice once a day or more & 17 & 25 & 0.09 & 20 & 32 & 0.23 \\
\hline Cooked green vegetables five times a week or more & 10 & 39 & $<0.0001$ & 27 & 44 & 0.08 \\
\hline Cooked root vegetables five times a week or more & I & 22 & $<0.001$ & 10 & 27 & 0.06 \\
\hline Raw vegetables or salad twice a week or more & 25 & 45 & 0.001 & 40 & 59 & 0.05 \\
\hline Use skimmed or semi-skimmed milk & 50 & 63 & 0.03 & 50 & 69 & 0.04 \\
\hline Oil-rich fish less than once a month & 43 & 33 & 0.09 & 27 & 33 & 0.59 \\
\hline Potatoes, pasta or rice five times a week or more & 25 & 64 & $<0.0001$ & 30 & 69 & $<0.0001$ \\
\hline Pulses twice a week or more & 32 & 67 & $<0.0001$ & 30 & 58 & 0.004 \\
\hline Breakfast cereal once a day or more & 58 & 38 & 0.0007 & 50 & 38 & 0.25 \\
\hline Usually eat wholemeal bread & 6 & 10 & 0.29 & 20 & 16 & 0.73 \\
\hline
\end{tabular}

I. General population subjects interviewed in Scottish Health Survey (Scottish Executive Health Department, 1998) and the Scottish targets are: I, average intake of fruit and vegetables to double; 2 , average intake of fat (especially saturated) to reduce; 3 , oil-rich fish consumption to double; 4 , complex carbohydrate consumption to increase by $25 \%$; 5 , bread intake, mainly wholemeal, to increase by $45 \%$. 
Table 3 Dietary choices of patients and of people in social class V in Scotland

\begin{tabular}{|c|c|c|c|c|c|c|}
\hline & \multicolumn{3}{|c|}{ Males } & \multicolumn{3}{|c|}{ Females } \\
\hline & Patients $(n=72)$ & Social class V $(n=191)$ & $P\left(\chi^{2}\right)$ & Patients $(n=30)$ & Social class V $(n=279)$ & $P\left(\chi^{2}\right)$ \\
\hline & $\%$ & $\%$ & & $\%$ & $\%$ & \\
\hline Cooked green vegetables five times a week or more' & 10 & 32 & 0.004 & & & NS \\
\hline Cooked root vegetables five times a week or more' & 1 & 19 & 0.006 & & & NS \\
\hline Raw vegetables or salad twice a week or more ${ }^{l}$ & 25 & $4 I$ & 0.03 & & & NS \\
\hline Potatoes, pasta or rice five times a week or more & 25 & 62 & $<0.0001$ & 30 & 58 & 0.003 \\
\hline Pulses twice a week or more & 32 & 69 & $<0.0001$ & 30 & 63 & 0.0009 \\
\hline
\end{tabular}

I. Data for female patients not significantly different from those for social class $V$ and not shown.

population in Scotland. However, almost all of our patients were unemployed and living on state benefits. The Scottish Health Survey (Scottish Executive Health Department, 1998) does not report the dietary habits of the unemployed but does present findings by social class. Those in social class $\mathrm{V}$ had the poorest diet. We therefore compared our patients with social class $\mathrm{V}$ individuals. Fewer males with schizophrenia reached acceptable levels for the consumption of vegetables, potatoes, pasta or rice, and pulses; fewer females reached acceptable levels for the consumption of potatoes, pasta or rice, and pulses (Table 3).

\section{Smoking habits}

Of the patients, $71(70 \%)$ were current smokers, $14(14 \%)$ had given up smoking and $14(14 \%)$ had never smoked. The mean age at starting smoking was 18 years $($ s.d. $=6)$ and the mean number of cigarettes smoked daily was 27 (s.d.=14). Of those who smoked cigarettes, 38 (54\%) were heavy smokers $(\geqslant 20 /$ day) and $40(54 \%)$ smokers wanted to give up. The mean reasons for smoking were: 'enjoy it' (49\%); 'to relax' (43\%); 'it's a habit/addiction' $(34 \%)$. There were no significant between-gender differences in rates of smoking or number of cigarettes smoked per day. More patients were smokers than members of the general population (Scottish Executive Health Department, 1998) $\left(70 / 101\right.$ v. 3183/9047; $\chi^{2}=49.28$, d.f. $=1, P<0.0001)$.

With regard to fruit and vegetable intake, current smokers compared with non-smokers were consuming fewer portions per week of fruit and vegetables $($ mean $=14 \quad($ s.d. $=12) \quad v$. mean $=22$ (s.d.=19); $t=2.73$, d.f. $=100, P=0.007$ ).

\section{Body mass index and physical activity}

The patients' BMI and waist measurements are shown in Table 4; 25 (86\%) females and $50(70 \%)$ males were either overweight or obese (which is a nonsignificant between-gender difference). Two had a BMI of $\geqslant 40 \mathrm{~kg} / \mathrm{m}^{2}$, that is, they were morbidly obese. Significantly more female patients than female controls in the general population were overweight or obese but there was no difference between male patients and controls; 41 $(57 \%)$ males and $18(60 \%)$ females considered themselves to be physically active. They spent a mean of 5.8 (s.d.=5.4) and 6.4 (s.d.=5.2) hours per week, respectively, on physical activity (which is a non-significant between-gender difference).

\section{Blood measurements}

Various blood measurements were carried out to assist in the assessment of nutritional status and cardiovascular risk (see below) (Table 5). Where possible, reference or target ranges are provided. Only two patients had an $\alpha$-tocopherol:cholesterol ratio below 2.25 , which is considered the

Table 4 Body mass index (BMI)

\begin{tabular}{|c|c|c|c|c|c|c|}
\hline & \multicolumn{2}{|c|}{ Males } & \multicolumn{2}{|c|}{ Females } & \multicolumn{2}{|c|}{ Total } \\
\hline & $\begin{array}{c}\text { Patients } \\
(n=72)\end{array}$ & $\begin{array}{c}\text { General } \\
\text { population' } \\
(n=3606)\end{array}$ & $\begin{array}{l}\text { Patients } \\
(n=29)\end{array}$ & $\begin{array}{c}\text { General } \\
\text { population' } \\
(n=46 \mathrm{II})\end{array}$ & $\begin{array}{l}\text { Patients } \\
(n=10 I)\end{array}$ & $\begin{array}{c}\text { General } \\
\text { population' }^{\prime} \\
(n=8217)\end{array}$ \\
\hline \multicolumn{7}{|l|}{ BMI, kg/m² (n(\%)) } \\
\hline$<18.5$ & $3(4)$ & 1370 (39) & I (4) & (46) & $4(4)$ & 3482 (47) \\
\hline $18.5-24.9$ & $19(26)$ & $13 / 0(38)$ & $3(10)$ & $2112(46)$ & $22(22)$ & $3482(42)$ \\
\hline $25-29.9$ & $32(45)^{2}$ & & $12(4 I)^{3}$ & & $44(43)^{4}$ & \\
\hline $30-39.9$ & $18(25)$ & $2236(62)$ & II (38) & $2499(54)$ & $29(29)$ & $4735(58)$ \\
\hline$\geqslant 40$ & $0(0)$ & & $2(7)$ & & $2(2)$ & \\
\hline Waist circumference (cm (s.d.)) & $99(12)$ & & $98(15)$ & & $99(13)$ & \\
\hline
\end{tabular}

I. Taken from Scottish Health Survey (Scottish Executive Health Department, 1998).

2. Overweight (BMI $25-29.9$ ) and obese $(B M I \geqslant 30) v$. others: $\chi^{2}=1.36$, d.f. $=I, P=0.24$.

3. Overweight and obese v. others: $\chi^{2}=10.66$, d.f. $=I, P=0.001$.

4. Overweight and obese v. others: $\chi^{2}=10.65$, d.f. $=I, P=0.001$. 
Table 5 Blood measurements

\begin{tabular}{|c|c|c|c|c|}
\hline Measurement & $\begin{array}{c}\text { Males } \\
\text { mean (s.d.) }\end{array}$ & $\begin{array}{c}\text { Females } \\
\text { mean (s.d.) }\end{array}$ & $\begin{array}{l}\text { Reference or } \\
\text { target range }\end{array}$ & $\begin{array}{c}\text { Outside normal } \\
\text { range, } n(\%)\end{array}$ \\
\hline Folate $(\mathrm{mg} / \mathrm{l})$ & $7.7(5.3)$ & $6.6(3.5)$ & $2.1-13.9$ & $2(2 \%)$ \\
\hline Cholesterol:HDL ratio & $5.5(I .7)$ & $5.1(1.9)$ & $<5$ & $46(53 \%)$ \\
\hline Retinol $(\mu \mathrm{mol} / \mathrm{l})$ & $1.61(0.56)$ & $\mathrm{I} .64(0.66)$ & $1.05-2.80^{\prime}$ & $9(11 \%)$ \\
\hline$\alpha$-Tocopherol $(\mu \mathrm{mol} / \mathrm{I})$ & $23.2(7.9)$ & $25.1(8.5)$ & II.6-46.4' & $4(5 \%)$ \\
\hline$\alpha$-Tocopherol:cholesterol ratio & $4.36(1.31)$ & $4.11(1.16)$ & $>2.25$ & $2(2.3)$ \\
\hline$\alpha$-Carotene $(\mu \mathrm{mol} / \mathrm{l})$ & $0.037(0.037)$ & $0.056(0.037)$ & - & - \\
\hline$\beta$-Carotene $(\mu \mathrm{mol} / \mathrm{l})$ & $0.24(0.19)$ & $0.30(0.26)$ & $0.19-1.58$ & 33 (42\%) \\
\hline Vitamin $C(\mu \mathrm{mol} / \mathrm{l})$ & $38.9(24.2)$ & $40.1(33.6)$ & $34-114^{1}$ & 37 (49\%) \\
\hline
\end{tabular}

I. See Burtis \& Ashwood (1999).

HDL, high-density lipoprotein.

Table 6 Mental state assessment: Positive and Negative Syndrome Scale

\begin{tabular}{lccc}
\hline Sub-scale & $\begin{array}{c}\text { Male }(n=70) \\
\text { mean score (s.d.) }\end{array}$ & $\begin{array}{c}\text { Female }(n=30) \\
\text { mean score (s.d.) }\end{array}$ & $\begin{array}{c}\text { Total }(n=100) \\
\text { mean score (s.d.) }\end{array}$ \\
\hline Positive symptoms sub-scale & $14(4)$ & $14(6)$ & $14(5)$ \\
Negative symptoms sub-scale & $19(6)$ & $19(5)$ & $19(6)$ \\
General psychopathology sub-scale & $31(8)$ & $33(7)$ & $32(7)$ \\
Total score & $64(15)$ & $66(15)$ & $65(15)$ \\
\hline
\end{tabular}

lowest satisfactory value (Panel on Dietary Reference Values, 1991). However, 64 (74\%) patients had a ratio below 5.00, a value above which it may be desirable to prevent coronary heart disease (Hense et al, 1993). There were significant correlations between the cholesterol:HDL ratio and waist measurement $(r=0.23, P=0.03)$, and the total number of fruit and vegetable portions consumed and the plasma vitamin C concentration $(r=0.28, P=0.01)$.

\section{Risk of coronary heart disease and stroke}

All necessary blood tests and investigations to make a Framingham assessment were available for 84 patients. The mean 10 -year risk of coronary heart disease in males was $10.5 \%$ (s.d. $=8$ ) (compared with the general population value of $6.4 \%$ (s.d. $=6$ ); $t$-test: $t=3.33$, d.f. $=122, P=0.001)$ and in females was $7 \%(s . d .=6)$ (compared with the general population value of $4.1 \%$ (s.d. $=4$ ); $t$-test: $t=1.90$, d.f. $=42, P=0.06$ ). The mean 10 year risk for stroke in males was $4.2 \%$ $($ s.d.=4) (compared with the general population value of $2.3 \% \quad($ s.d. $=2) ; t$-test: $t=3.13$, d.f. $=122, P=0.002)$ and in females was $3.8 \% \quad($ s.d.=6) (compared with the general population value of $2.0 \%($ s.d. $=3$ ): $t$-test: $t=1.28$, d.f. $=42, P=0.21$ ).
There were no significant betweengender differences in the 10-year risk for coronary heart disease ( $t$-test: $t=1.92$, d.f. $=82, P=0.06)$ or for stroke $(t=0.37$, d.f. $=82, P=0.71$ ).

It has now been suggested (Wood $e t$ al, 1998) that individuals with a coronary heart disease risk of $30 \%$ or higher over 10 years should be treated, for example, with a statin. Treatment should then move progressively on to those with $\geqslant 15 \%$ coronary heart disease risk. In our patients one $(1 \%)$ female had $\geqslant 30 \%$ risk of coronary heart disease and eighteen $(28 \%)$ males and four $(18 \%)$ females had $a \geqslant 15 \%$ risk.

\section{Mental state assessment and medication}

The PANSS scores are shown in Table 6 . There were no statistically significant between-gender differences. With regard to antipsychotic medication the patients were divided into three groups: those patients receiving long-acting intramuscular typical antipsychotic medication with or without other antipsychotics $(n=27$, $27 \%$ ); those receiving oral typical medication with or without atypicals $(n=22$, $22 \%$ ); and those receiving atypicals alone $(n=43,43 \%)$. Six $(6 \%)$ were receiving no antipsychotic and medication was unknown in two patients. There were no significant differences in BMI in the three drug groups. Patients then were divided into those taking only typical medication, either oral or intramuscular $(n=36)$, and those taking only atypical medication $(n=41)$. There were no significant between-group differences in plasma glucose and serum lipid levels or in the BMI.

When the patients were divided into three groups on the basis of fruit and vegetable consumption, there were no significant differences between those consuming the most fruit and vegetables (range $=19-82$ portions per week; median=29) and those consuming the least $(0-7$ portions per week; median $=3)$ in scores on the positive, negative and general psychopathology sub-scales of the PANSS.

\section{DISCUSSION}

\section{Methodological issues}

Although almost half of the patients we approached refused to participate in the study, they did not differ from those who did participate in terms of gender distribution, age or living arrangements. We have no reason to think that their diet was very different from that of those who took part. However, the patients recruited came from a group who were already receiving considerable professional support in the community. We did not approach those who were living with well relatives. It is possible that their diets were more satisfactory.

The dietary questionnaire that we used assesses food intake retrospectively. It is by no means certain that a prospective weighed intake of food would have provided a more accurate assessment. However, the retrospective method offered us the advantage of assessing usual dietary patterns over a longer time-span. In addition, we did not think that the patients could cooperate sufficiently in what is a time-consuming and detailed task.

\section{Dietary habits}

Our patients were making poor dietary choices. First, with regard to fruit and vegetable intake, the average consumption was only 16 portions per week; the recommended intake is 5 portions per day (Heimendinger \& Van Duyn, 1995). Second, with regard to general aspects of diet, our patients (and especially the males) were making poorer choices in many more 
areas than not only members of the general population in Scotland but also those in Scotland with the poorest diet, namely those in social class V. A previous study (Brown et al, 1999) of community-based people with schizophrenia found that no one was consuming five or more portions of fruit and vegetables a day and that their diet was higher in fat and lower in fibre than the general population's.

Why is their diet so poor? There are several possible reasons. First, all but two patients were unemployed. The diet of the unemployed is probably worse than that of the employed (Smith, 1985). Second, most of our patients were smokers. In the general population the diets of smokers, both men and women, are worse than of non-smokers (Osler et al, 2002); and in the present study we found that, in people with schizophrenia, smokers had a lower intake of fruit and vegetables than nonsmokers. Third, although we found no difference in mental state scores between those who had an adequate or low intake of fruit and vegetables, negative schizophrenic symptoms such as apathy may lead patients to consume more of the less healthy convenience foods.

\section{Bloods}

The majority of our patients had an elevated cholesterol:HDL ratio and a low $\alpha$-tocopherol:cholesterol ratio. These observations are likely to be related to factors such as poor nutrition (increased saturated fat intake), obesity, lack of exercise and smoking. All of these factors were common in our patients. However, the number of patients who were folate deficient was very low (only two individuals). It is possible that the number of patients taking cereal, which is often supplemented with folate, may explain this finding.

Our patients were found to have serum concentrations of $\alpha$ - and $\beta$-carotene similar to subjects in the lowest quartile for fruit and vegetable consumption, investigated more than 10 years ago in a study of British adults (Billson et al, 1999). The various carotenoid concentrations were much lower than the baseline values in a recently published fruit and vegetable intervention trial from Oxford (John et al, 2002). The carotenoid results in our patients are indicative of a diet that contains little in the way of fruit and vegetables, and reflect the small number of portions of fruit and vegetables that our patients consumed. Vitamin C, a water-soluble vitamin, is present at plasma concentrations that appear no different from those recorded in a healthy population recruited from Oxfordshire in the UK (John et al, 2002). It is difficult to explain why two such diverse groups of people with differing fruit and vegetable consumption should have such similar vitamin $\mathrm{C}$ concentrations.

Glucoregulatory and lipid abnormalities have been reported previously to be more common in patients receiving atypical rather than standard antipsychotics (Meyer, 2001; Newcomer et al, 2002). Such differences were not found in the present study. However, non-fasting blood samples were collected, which may have made it more difficult to detect differences, and the numbers in each group were small.

\section{Smoking}

In addition to having a poor diet, $70 \%$ of patients were smokers, which is twice as many as in the general Scottish population; $54 \%$ of those who smoked were heavy smokers, compared with $11 \%$ in the general population in south-west Scotland (Waldron et al, 1995). The age at which they started smoking was similar to that of the general population in south-west Scotland (Waldron et al, 1995) and was, on average, six years before the first episode of illness. This finding, reported previously (Kelly \& McCreadie, 1999), emphasises that it is unlikely that the symptoms of the illness itself lead people to start smoking.

The present study is the baseline for a dietary intervention. Attempts to help people with schizophrenia to give up smoking should no doubt be tried. However, so far such attempts have met with little success (Lavin et al, 1996).

\section{Body mass index}

The majority of patients (73\%) were overweight or obese. This figure is higher than in the general Scottish population in 1997 (60\%) (Scottish Executive Health Department, 1998). This may be due in part to lack of physical exercise because only $59 \%$ considered themselves physically active. However, this figure is very similar to that found in the general population living in a deprived community in the west of Scotland, where the same questionnaire was used (56\%) (Lowther et al, 2002). Antipsychotic medication is well known to produce weight gain and only $6 \%$ of patients in the present study were not receiving medication. Smoking usually reduces the BMI. A raised BMI at any age and in both genders is associated with an increased mortality (Calle et al, 1999), but the combination of overweight or obesity with smoking presents a particularly potent risk for coronary heart disease (Manson et al, 1990).

\section{Framingham assessment}

In view of the patients' eating and smoking habits and their body weight, it is no surprise that they had a predicted increased risk over the next ten years of both coronary heart disease (mean 9.6\%) and stroke $(4.1 \%)$; the difference in risk between male patients and the general population was statistically significant, and $26 \%$ of patients had a 10 -year risk of coronary heart disease $\geqslant 15 \%$, a level at which active treatment would be advised (Wood et al, 1998). Thus, people with schizophrenia constitute a highrisk group needing priority for cardiovascular risk reduction. One of the particular hazards of weight gain (even before reaching the BMI threshold for obesity) is of developing type 2 diabetes. The proportion of patients in the present study reporting that they had diabetes was $2 \%$. This is lower than other reports of the current prevalence of diabetes in people with schizophrenia: 9-14\% (Dixon et al, 2000). However, there were few female patients in our study; diabetes is twice as common in females with schizophrenia compared with males (Dixon et al, 2000).

We conclude that the lifestyle of people with schizophrenia, as measured by diet, smoking habits, weight and exercise, must give cause for concern in relation to coronary heart disease. Primary care services should address these issues. It has been suggested (NHS Executive, 1999) that general practitioners should be paid for assessing the physical health of people with severe mental illness and make any necessary interventions. For this to be successful, practices would need to be able to identify these patients and develop effective screening mechanisms (Phelan et al, 2001). In addition, care given from secondary services to people with schizophrenia in the community, a vulnerable section of the population, must be concerned also with physical health, otherwise the risk of cardiovascular and other disease will remain high and patients will die prematurely. This is the principal reason why we have 
embarked on a study to determine whether their diet can be improved, namely through the provision of free fruit and vegetables. This may be one way in which it is possible to improve their physical health; other ways might include such things as health promotion schemes and the prescription of vitamin supplements.

\section{ACKNOWLEDGEMENTS}

We thank the patients and care staff for their cooperation.

The members of the Scottish Schizophrenia Lifestyle Group are: Crichton Royal Hospital, Dumfries: Professor R. G. McCreadie, Mrs S. Williams, Ms E. Brown, Mrs S. Farrington, Mrs M. Hunter, Dr S. Macdonald, Dr J. White, Dr I. Kader, Dr S. Holmes, Dr G. Morrison, Mrs S. Wall, Mrs C. Colwell; Gartnavel Royal Hospital, Glasgow: Dr C. Kelly, Dr M. Connolly, Ms D. Fraser, Mrs C. Gray, Dr J. Ellison, Dr R. Brogan, Dr D. Brown; Dumfries \& Galloway Royal Infirmary: Dr J. R. Paterson, Miss H. Barrington; Mrs G. J. Baxter; Royal Infirmary, Glasgow: Professor M. Lean, Dr C. Hankey; Rowett Research Institute, Aberdeen: Dr G. Duthie. Dr Duthie received additional funding from the Scottish Executive Environment and Rural Affairs Department.

\section{REFERENCES}

American Psychiatric Association (1994) Diagnostic and Statistical Manual of Mental Disorders (4th edn) (DSM-IV). Washington, DC: APA.

Billson, H., Pryer, J. A. \& Nichols, R. (1999) Variation in fruit and vegetable consumption among adults in Britain. Analysis from the dietary and nutritional survey of British adults. European Journal of Clinical Nutrition, $\mathbf{5 3}$, 946-952.

Brown, S., Birtwistle, J., Roe, L., et al (1999) The unhealthy lifestyle of people with schizophrenia. Psychological Medicine, 29, 697-70I.

Burtis, C. A. \& Ashwood, E. R. (1999) Tietz Textbook of Clinical Chemistry (3rd edn). Philadelphia, PA: Saunders.

Calle, E. E., Thun, M. J., Petrelli, J. M., et al (1999) Body mass index and mortality in a prospective cohort of US adults. New England Journal of Medicine, 34I, 1097-1105.

Dixon, L., Weiden, P., Delahunty, J., et al (2000) Prevalence and correlates of diabetes in natural schizophrenia samples. Schizophrenia Bulletin, 26, 903-912.

Gillman, M.W. (1996) Enjoy your fruits and vegetables. BMJ, 313, 765-766.

Heimendinger, J. \& Van Duyn, M. A. S. (1995) Dietary behaviour change: the challenge of recasting the role of fruit and vegetables in the American diet. American Journal of Clinical Nutrition, 61, 1397S-140IS

Hense, H. W., Stender, M., Bors, W., et al (1993) Lack of an association between serum vitamin $E$ and myocardial infarction in a population with high vitamin $E$ levels. Atherosclerosis, 103, 2I-28.

Hingorami, A. D. \& Vallance, P. (1999) A simple computer programme for guiding management of cardiovascular risk factors and prescribing. BMJ, 318, $101-105$

\section{CLINICAL IMPLICATIONS}

- The diet of people with schizophrenia is poor; most are smokers and most are overweight or obese.

- People with schizophrenia, especially males, have a predicted increased risk of both coronary heart disease and stroke.

- 'Associative outreach' from secondary care mental health services must be concerned not only with mental but also with physical health.

\section{LIMITATIONS}

- The patients recruited were already receiving considerable professional help in the community. We did not approach those living with well relatives.

- The dietary questionnaire assessed food intake retrospectively.

- Blood samples to assess micronutrients were non-fasting.

R. G. McCREADIE, DSc, Department of Clinical Research, Crichton Royal Hospital, Dumfries DGI 4TG, UK. Tel: +44 1387 244000; fax: +44 1387 257735; e-mail: rgmccreadie_crh@compuserve.com

(Received I3 March 2003, final revision 2I July 2003, accepted 2I July 2003)

John, J. H., Ziebland, S., Yudkin, P., et al (2002) Effects of fruit and vegetable consumption on plasma antioxidant concentrations of blood pressure: a randomised controlled trial. Lancet, 359, 1969-1674.

Kay, S. R., Fiszbein, A. \& Opler, L. A. (1987) The positive and negative syndrome scale (PANSS) for schizophrenia. Schizophrenia Bulletin, 13, 261-276.

Kelly, C. \& McCreadie, R. G. (1999) Smoking habits, current symptoms and premorbid characteristics of Nithsdale schizophrenic patients. American Journal of Psychiatry, 156, 175I-1757.

Lavin, M. R., Siris, S. G. \& Mason, S. E. (1996) What is the clinical importance of cigarette smoking in schizophrenia? American Journal of Addiction, 5, 189-208.

Lowther, M. P., Mutrie, N., Loughlan, C., et al (1999) Development of a Scottish physical activity questionnaire: a tool for use in physical activity interventions. British Journal of Sports Medicine, 33, 244-249.

_ , _ \& Scott, E. M. (2002) Promoting physical activity in a socially and economically deprived community: a 12 month randomised controlled trial of fitness assessment and exercise consultation. Sport Science, 20, 577-588.

Manson, J. E., Colditz, G. A., Stampfer, M. J., et al (1990) A prospective study of obesity and risk of coronary heart disease in women. New England Journal of Medicine, 323, 882-889.

McCreadie, R. G., Macdonald, E., Blacklock, C., et al (1998) Dietaryintake of schizophrenic patients in Nithsdale, Scotland: case-control study. BMy, 317, 784-785.

Meyer, J. M. (200I) Novel antipsychotics and severe hyperlipidemia. Journal of Clinical Psychopharmacology, 21 369-374.

Mortensen, P. B. \& Juel, K. (1993) Mortality and causes of death in first admitted schizophrenic patients. British Journal of Psychiatry, 163, 183-189.
NHS Executive (1999) Health Service Circular 1999/107. London: NHSE.

Newcomer, J.W., Haupt, D. W., Fucetola, R., et al (2002) Abnormalities in glucose regulation during antipsychotic treatment of schizophrenia. Archives of General Psychiatry, 59, 337-345.

Osler, M., Tjonneland, A., Suntum, M., et al (2002) Does the association between smoking status and selected healthy foods depend on gender? A population-based study of 54417 middle-aged Danes. European Journal of Clinical Nutrition, 56, 57-63.

Panel on Dietary Reference Values of the Committee on Medical Aspects of Food Policy (1991) Dietary Reference Values for Food Energy and Nutrients for the United Kingdom. Department of Health Report on Health and Social Subjects. London: HMSO.

Phelan, M., Stradins, L. \& Morrison, S. (200I) Physical health of people with severe mental illness. BMJ, 322, 443-444.

Scottish Executive Health Department (1998) The Scottish Health Survey, vols I and II. Edinburgh: Scottish Executive Health Department.

Scottish Office Department of Health (1996) Eating for Health: a Diet Action Plan for Scotland. Edinburgh: Scottish Office Department of Health.

- (1999) Towards a Healthier Scotland. White Paper on Health. Edinburgh: Stationery Office.

Smith, R. (1985) 'Gissa job'. The experience of unemployment. BMJ, 29I, 1263-1266.

Waldron, G., Chalmers, J., Bone, A., et al (1995) Health and Lifestyles in Dumfries and Galloway in 1995. Dumfries: Dumfries and Galloway. Health Board.

Wood, D., Durrington, P., Poulter, N., et al (1998) Joint British recommendations on prevention of coronary heart disease in clinical practice. Heart, 80 (suppl. 2), SI-S29. 